\title{
MINIREVIEW
}

\section{SARS-CoV-2: Zoonotic origin of pandemic coronavirus}

\author{
S. VILCEK \\ Department of Epizootiology and Parasitology, University of Veterinary Medicine and Pharmacy, Komenskeho 73, \\ Kosice, Slovak Republic
}

Received July 14, 2020; accepted July 20, 2020

\begin{abstract}
Summary. - A novel disease, of unknown origin, causing a deadly pneumonia of human patients was reported in December 2019 in Wuhan, Hubei province of China. Later called coronavirus disease (COVID-19), it rapidly spread across China and worldwide. Intensive research revealed that the etiological agent of the global COVID-19 pandemic was a novel coronavirus named severe acute respiratory syndrome coronavirus 2 (SARS-CoV-2). The SARS-CoV-2 genome contains typical coronavirus genes but the receptor binding domain (RBD) in the $S$ protein is highly specific. The site for furin-like protease cleavage of the $S$ protein into $\mathrm{S} 1$ and $\mathrm{S} 2$ subunits is also unique. Further analyses suggested that SARS-CoV-2 is of zoonotic origin. The analysis of the SARS-CoV-2 genome, especially the $S$ gene, shows that natural evolutionary process between a bat-CoV and a pangolin-CoV or other animal coronavirus could have been important in creating SARS-CoV-2, with transmission of novel virus to the human population. On the other hand, new analyses indicate that SARS-CoV-2 is not a recombinant virus.
\end{abstract}

Keywords: COVID-19; SARS-CoV-2; genome; bat coronavirus; pangolin coronavirus

\section{Introduction}

At present we are victims of unexpected outbreaks of coronavirus disease (COVID-19) (WHO, 2020), which developed into a pandemic with more than 12.8 millions of laboratory confirmed infected patients and over 567.000 deaths in 216 countries (WHO; July14,2020). While no one expected such rapid spread of COVID-19 around the globe, coronavirus experts have assumed that novel coronavirus variants with epidemic potential would emerge (Cui et al., 2019).

E-mail: Stefan.Vilcek@uvlf.sk; phone: +421(0)915 984654. Abbreviations: $\mathrm{ACE} 2$ = angiotensin-converting enzyme 2; COVID-19 = coronavirus disease 2019; MERS = Middle East respiratory syndrome; SARS = severe acute respiratory syndrome; SARS-CoV-2 = SARS coronavirus $2 ; \mathrm{RBD}=$ receptor binding domain
Coronaviruses are causative agents of mild and severe diseases. There are seven coronaviruses affecting the human population. Infections with alphacoronaviruses 229E, NL63 and betacoronaviruses OC43 and HKU1 may cause diarrhea and mild upper respiratory tract syndromes. SARS-CoV, which was the causative agent of SARS (severe acute respiratory syndrome) detected in China, Hong Kong and Taiwan in 2002 and 2003, could infect the lower respiratory tract (Cheng et al., 2007). A similar situation was observed with MERS outbreaks (Middle East respiratory syndrome) as a result of MERS-CoV infection in Saudi Arabia in 2012 (Chan et al., 2015). Novel coronavirus SARS-CoV-2, previously called "2019-novel coronavirus (2019-nCoV)", causing COVID-19, infects lung tissue with severe respiratory illness, which can result in fatal pneumonia (Cao et al., 2020; Lu et al., 2020a,b; Wu et al., 2020; Zhu et al., 2020).

Coronaviruses infect not only humans but also a broad spectrum of mammals, such as bats, rodents, swine, cat- 
tle, horses, cats, pangolins and others as well as snakes and birds (chickens, turkeys, pheasants). Coexistence in different hosts may provide additional evolutionary opportunities through genome recombination, further driving inter-species spread (Decaro and Lorusso, 2020). Taking into account all these facts, an outbreak due to a novel coronavirus may not be so unexpected.

Shortly after development of COVID-19 pandemic, an explosion of papers of variable scientific quality have been presented on web portals and published in scientific journals. This review summarizes the current thinking related to the origin of SARS-CoV-2 from a critical analysis of papers with solid scientific data.

\section{The coronavirus virion}

The virus genome of the family Coronaviradae, where SARS-CoV-2 belongs, is non-segmented positive-oriented RNA of 27-32 kb in size (Cui et al., 2019). Two thirds of this genome encodes 16 non-structural proteins and one third is responsible for the synthesis of viral structural proteins. Besides the membrane (M), envelope (E) and nucleocapsid $(\mathrm{N})$ proteins, the most important is the spike protein (S) (Decaro and Lorusso, 2020), which projects from the virion surface and interacts with cellular receptors. The $S$ protein precursor is cleaved by a cellular protease into two $S 1$ and S2 subunits. The S1 subunit contains the RBD (receptor binding domain), whilst S2 takes part in fusion of the virus and cell membranes (Belouzard et al., 2009).

\section{Identification of novel coronavirus SARS-CoV-2}

The first identification of a novel disease came from doctors and epidemiologists. They reported pneumonia cases of unknown origin in Wuhan, Hubei province in China, in December 2019. The patients shared history of exposure to Huanan seafood market located in the city. Clinical symptoms were high fever, severe respiratory illness and high mortality (Huang et al., 2020). These symptoms, connected to a seafood market in the winter season were suspicious of a coronavirus infection, as SARS-CoV, the etiological agent of SARS, was discovered under similar conditions in 2002 (Cheng et al., 2007).

The first confirmation that a coronavirus was present in clinical samples from human cases of the novel syndrome was obtained from an RT-PCR assay employing pan-coronavirus primers (Zhou et al., 2020a). The virus was also detected in clinical samples by deep sequencing (Huang et al., 2020; Wu et al., 2020).

The alignment of coronavirus sequences and SARSCoV-2 genome confirmed that the novel coronavirus had

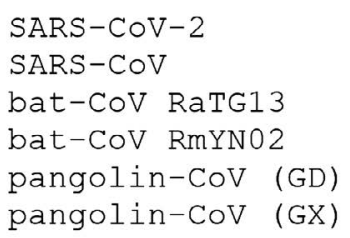

Fig. 1

Alignment of the key amino acids in the RBD of the $S$ protein GD - Chinese province Guangdong, GX - Chinese province Guangxi (Andersen et al., 2020; Lam et al.,2020). "Position of amino acid in S protein of SARS-CoV-2 (data from Wan et al., 2020).

a similar genome organisation to known coronaviruses (Chan et al., 2020; Huang et al., 2020; Wu et al., 2020; Zhou et al., 2020a) and that the virus belonged to the genus Betacoronavirus, the subgenus Sarbecovirus. The novel coronavirus was officially named SARS-CoV-2 (Gorbalenya et al., 2020). Further studies revealed that the SARS-CoV-2 genome contains several unique characteristics, especially in the $S$ gene, different from other coronaviruses.

\section{Unique feature of the SARS-CoV-2 S gene}

The alignment of coronavirus $S$ gene sequences identified two regions in $S$ protein with characteristics specific for SARS-CoV-2.

\section{Specific receptor binding domain}

Genetic analysis revealed 5-6 key specific amino acids in the RBD of the SARS-CoV-2 S protein (Fig. 1), which were significantly different from SARS-CoV (Andersen et al., 2020; Wan et al., 2020). Nevertheless, SARS-CoV-2 recognised the same cellular receptor ACE2 (angiotensinconverting enzyme 2 ) on human lung cells as had been determined for SARS-CoV (Hoffmann et al., 2020a; Wan et al., 2020; Zhou et al., 2020a). The interaction of the S protein SARS-CoV-2 with human ACE2 receptor was intensively examined by structural studies (Kumar et al., 2020; Lan et al., 2020; Letko et al., 2020; Wan et al., 2020; Watanabe et al., 2020), by crystallographic studies and cryo-electron microscopy (Wang et al., 2020a; Wrapp et al., 2020; Yan et al., 2020; Yuan et al., 2020), and by biochemical (Kumar et al., 2020; Ou et al., 2020; Shang et al., 2020a) and antigenic analyses (Kumar et al., 2020). Computational structural analysis also revealed that the RBD-ACE2 interaction on human cells is not optimal and may improve during further evolutionary adaptation (Wan et al., 2020), for example by amino acid mutation, most probably leading to new human health problems. 


$\begin{array}{lr}\text { SARS-COV-2 } & \begin{array}{r}\boldsymbol{V} \\ \text { SARS-COV }\end{array} \\ \text { bat-COV } & \text { LL----RS } \\ \text { bat-CoV RmYN02 } & \text { NS----RS } \\ \text { pangolin-CoV } & \text { NSP-AAR- }\end{array}$

Fig. 2

Alignment of amino acids in the region of the cleavage site of the $S$ protein from different coronaviruses

Position in SARS-CoV-2 S protein: $679-686 ; \boldsymbol{\nabla}$ - polybasic furin-like cleavage site for SARS-CoV-2 (data from Walls et al., 2020; Zhou et al., 2020b.).

\section{New polybasic furin-like protease cleavage site}

The alignment of the coronavirus $S$ gene nucleotide sequences revealed not only a specific RBD but also a unique insertion of 12 nucleotides, encoding 4 amino acids: PRRA (Fig. 2). This insertion created a new polybasic furin-like cleavage site RRAR (Fig.2, underlined sequence) for the cleavage of the S protein into the S1 and S2 subunits (Jaimes et al., 2020; Walls et al., 2020). The cleavage at the furin-cleavage site facilitates the adoption of the conformation that is required for $S$ glycoprotein to bind to the ACE2 receptor (Wrobel et al., 2020). Just recently, it has been reported that polybasic furin-like protease cleavage site is essential for SARS-CoV-2 to infect human lung cells (Hoffmann et al., 2020b).

Although the origin of this insertion is not clear, recent finding indicates that such molecular event is not rare. The novel bat coronavirus strain RmYN02 was identified with the insertion of three amino acid residues, PAA, at the junction of S1 and S2 (Fig. 2), where is located PRAA insertion in SARS-CoV-2. This is evidence that insertion at this location may occur and it is a natural and expected component of coronavirus evolution (Zhou et al., 2020b).

The mechanism of penetration for novel coronavirus into human cells is similar as for SARS-CoV. The viral S protein binds with RBD to ACE2 receptor. The cellular TMPRSSA (type II transmembrane serine protease) is employed by SARS-CoV-2 for S protein priming which is essential for viral entry into cells and encompasses $S$ protein cleavage at the S1/S2 junction (Hoffmann et al., 2020a).

\section{Is SARS-CoV-2 of artificial or zoonotic origin?}

The discovery of the unique properties of the SARSCoV-2 S gene helped, at least partially, to explain the origin of this novel coronavirus.

The first suspicion, which mostly developed outside of the scientific community, was an artificial origin of the virus. However, as mentioned above, the $S$ protein of novel coronavirus contains specific structures not recognised in other coronaviruses and it is hard to suppose that they could have been designed in the laboratory with strong biological effect.

The putative artificial origin of SARS-CoV-2 was promoted by a manuscript presented on the web portal bioRxiv, which was submitted by authors from the Indian Institute of Technology in New Delhi (Pradham et al., 2020). They found short amino acid sequence stretches (4-12 amino acids) in the S protein of SARS-CoV-2, which were identical or similar with sequences of the key structural gp120 and gag HIV proteins. Their finding, supported by Luc Montagnier, the co-discoverer of HIV and Nobel prize winner, sustained speculation that SARS-CoV-2 originated from the development of an AIDS vaccine employing coronavirus constructs. However, after the peer-review process, the authors withdrew their manuscript, because the "unique amino acid HIV sequences" in coronavirus genome could be also found in the genomes of other viruses, including other coronaviruses (Xiao et al., 2020a; Zhang et al., 2020a). A bioinformatics analysis indicated that the SARS-CoV-2 genome was unrelated to known artificial coronaviruses (Dallavilla et al.,2020). These scientific facts displaced the idea of the artificial origin SARS-CoV-2 to the field of unsubstantiated "conspiracy theories".

The natural origin of the novel coronavirus should be deduced from critical scientific evaluation. There are two principal theories: i) natural selection of virus in an animal host and zoonotic transfer to human population, ii) natural selection in humans following zoonotic transfer (Andersen et al., 2020). At present, it is hard to decide which theory is correct.

The idea that the virus was selected in an animal host before zoonotic transfer was based on the observation that the novel virus was identified at a seafood market where fish, shellfish and a variety of live animals, such as rabbits, hedgehogs, marmots, badgers, minks, snakes, poultry and birds were sold or killed for human consumption. A part of Chinese people believe in the medicinal value as well as the health-promoting effects associated with the consumption of certain wild game animal meats and their products. In addition, all animals were kept together in close contact and to people, which was an ideal situation for the inter-species zoonotic transmission of infection (Zhang and Holmes, 2020). It would not be surprising if some recombination of viral genomes occurred under these circumstances.

The first speculation on the origin of the novel coronavirus was based on data that SARS-CoV-2 has most similar genetic information with bat coronovirus and most similar codon usage bias with snake. Thus, the snakes or bats could be the carrier of the novel coronavirus ( $\mathrm{Ji}$ 
et al., 2020). While most of the scientific community did not accept snakes as likely animal carriers for a novel human virus (Zhang et al., 2020a), bats were considered good candidates, as SARS and MERS also evolved from bat coronaviruses.

Another study revealed that the SARS-CoV-2 genome is $96 \%$ identical to the coronavirus genome RaTG13 of a bat (Rhinolophus affinis) originating from Yunnan province, whereas the shared identity of SARS-CoV and SARS-CoV-2 genomes is only $79.6 \%$ (Zhou et al., 2020a). These findings were supported by phylogenetic analysis of SARS-CoV-2 and bat coronaviruses (bat-CoV), where SARS-CoV-2 and bat-CoV RaTG13 had the closest relationship of all coronaviruses analysed (Zhou et al., 2020a). Nevertheless, the RBD sequences in their respective $S$ proteins were different, including differences in the 5-6 key amino acids (Fig. 1). Surprisingly, the bat-CoV RaTG13 could use the human ACE2 receptor (Shang et al., 2020b) but SARS-CoV-2 binds about 1,000-fold tighter to ACE2 receptor than batCoV RaTG13 (Wrobel et al.,2020). Despite that, this bat-CoV is most probably not the direct progenitor of SARS-CoV-2 because it has no other characteristics of the SARS-CoV-2 $S$ protein. It seems that there is some intermediate species for the transfer of SARS-CoV-2 to man, similar to what was observed for the transfer of SARS-CoV from bats to palm civets and then to man and MERS from bats to dromedary camels, which infected people (Sabir et al., 2016; Cui et al., 2020).

The search for animal intermediate species was facilitated by the work of Liu et al.(2019), published before the COVID-19 outbreaks. These authors conducted a metagenomics analysis of samples originating from pangolins (Manis javanica) that had been illegally transported from Malaysia to the Chinese province of Guangdong (GD) and containing many viruses, including coronaviruses similar to SARS-CoV. A retrospective NGS analysis of archival samples used in this work was performed by Lam et al. (2020) and revealed that the RBD in the S protein of a pangolin coronavirus, pangolin-CoV(GD), detected in pangolins originating from Guangdong, was $97.4 \%$ similar to RBD SARS-CoV-2, including complete identity to all the key amino acids (Fig. 1). Zhang et al. (2020b) confirmed this conclusion by analysis of metadata deposited by Liu et al. (2019). Phylogenetic analysis indicated a very close relationship between coronavirus sequences from the bat-CoV RaTG13 and pangolin sequences from Guangdong province. It should be pointed out that the pangolin-CoV(GD) had no polybasic S1/S2 cleavage site (Lam et al., 2020; Zhang et al., 2020b). These data suggest a possible role for bats and pangolins in the animal origin of SARS-CoV-2.

Meanwhile, other studies oriented on coronaviruses of pangolins were published. The isolated viral particles of pangolin-CoV detected under electron microscopy showed typical coronavirus morphology (Xiao et al., $2020 b)$. Analysis of pangolin samples again confirmed a close phylogenetic relationship of SARS-CoV-2, bat-CoV and pangolin-CoV(GD) (Liu et al., 2020), as well as almost complete identity of the key amino acids in the RBD of pangolin-CoV(GD) compared with SARS-CoV-2 (Liu et al., 2020; Xiao et al., 2020b; Zhai et al., 2020). A comparative analysis showed that the S proteins of SARS-CoV-2 and pangolin-CoV(GD) can potentially recognize ACE2 in both humans and pangolins (Xiao et al.2020b; Zhai et al., 2020; Zhang et al., 2020;) but binding affinity SARS-CoV-2 for pangolin ACE2 is significantly lower (Wang et al., $2020 b)$. Since the $S$ gene of pangolin-CoV(GD) lacks the polybasic furin-like cleavage site (Fig. 2), it is speculated that this unique cleavage site arose as a result of natural evolutionary process near the S1/S2 junction (Andersen et al., 2020).

To complete the picture, it should be mentioned that analysis of the pangolin samples from another Chinese province, Guangxi (GX) confirmed a close identity of pangolin-CoV(GX) and SARS-CoV-2 (around 90\%) but with differences in the $S$ protein $\mathrm{RBD}$, including the key amino acids (Fig. 1). These findings indicate that pangolins can be infected with several coronaviruses of different phylogenetic lineages (Lam et al, 2020).

Critical analysis suggests that SARS-CoV-2 does not originate directly from pangolin-CoV but bat-CoV and pangolin-CoV genetic material may be involved in creation of novel coronavirus (Andersen et al., 2020; Liu et al., 2020; Xiao et al., 2020b; Zhang et al., 2020b). Whether or not a coronavirus from another animal is involved in this process remains to be elucidated.

To make matters more complicated, it cannot be excluded that the new coronavirus developed after transfer from animal to man by selection within human hosts. This scenario assumes that the proteolytic cleavage site developed in people after they had been infected with a progenitor of SARS-CoV-2 (Andersen et al., 2020). The initial infection within the human population might not have been observed due to missing clinical signs.

\section{Future research}

Within a few months of the development of the COVID-19 pandemic, scientists have identified its aetiological agent as a novel coronavirus, SARS-CoV-2, and described its basic genetic properties. However, there are still more questions than answers as for example links between the genetics and the biology of the virus. Further research in this field is extremely urgent. Important scientific priorities will be: 
- deep characterization of novel coronavirus at the nucleotide and amino acid level, including study of biochemical, crystallographic, and immunological properties

- search for coronaviruses related to SARS-CoV-2 in wild and exotic animals and their characterization to better explain the evolutionary origin of the virus

- complex analysis of the interaction between SARSCoV-2 and its human host to search for antiviral agents and effective vaccines

More generally, it can be expected that the accumulation of data on the novel coronavirus will extend our knowledge on the evolution of the Coronaviridae family, which will improve our ability to deal with this and future coronavirus threats.

\section{Conclusion}

At present, we believe that the new pandemic coronavirus has resulted from an evolutionary process between genetic material of bat-CoV and maybe a coronavirus from other animal(s), perhaps pangolin-CoV, to create a modified virus able to transfer to man and cause a human pandemic. Virologists are convinced that SARS-CoV-2 is of zoonotic origin not a man-made virus (Andersen et al., 2020; Zhang a Holmes, 2020).

SARS-CoV-2, as etiological agent of COVID-19, is an excellent example of why it is so important to pay attention to the threat posed by zoonotic viruses. Three coronaviruses have transferred to man in the past 18 years, leading to two serious coronavirus epidemics caused by SARS-CoV (2003) and MERS-CoV (2012) and a pandemic caused by SARS-CoV-2 (2020). No doubt, it will only be a matter of time before a new coronavirus outbreak will arise in the future. However, our experience with COVID-19 should help us to be better prepared to fight new outbreaks in their early stages.

Acknowledgment. This work was supported by project APVV15-0415 from The Slovak Research and Development Agency. I would like to thank Dr David Paton, UK, for critical reading and English grammar correction of the manuscript.

\section{New important information after proof}

Research focused on SARS-CoV-2 origin is highly dynamic, with the development of new ideas. Recently, it has been published that SARS-CoV-2 is not a recombinant of any sarbecoviruses detected to date, and its receptorbinding motif, important for specificity to human ACE2 receptors, appears to be an ancestral trait shared with bat viruses and not one acquired recently via recombina- tion. Divergence dates between SARS-CoV-2 and the bat sarbecovirus reservoir were estimated from 1948 to 1982 , indicating that the lineage giving rise to SARS-CoV-2 has been circulating unnoticed in bats for decades (Boni et al., 2020).

Other authors (Frutos et al., 2020) claim in their questionable circulation model that SARS-CoV-2 is not of zoonotic origin. Bats, pangolins, and other animals are not responsible for the epidemics or pandemics affecting humans. The real triggers for epidemic and pandemics are the societal organization and society-driven human/ animal contacts and amplification loops provided by the modern human society, i.e. contacts, land conversion, markets, international trades, mobility, etc. According to the circulation model, what really prepares the ground for the epidemic is simply an accidental event, i.e. a mutation, recombination or reassortment in the virus genome. The virus is already present in an animal population close to humans or even in humans, and this mutation makes it more invasive and/or pathogenic.

\section{References}

Andersen KG, Rambaut A, Lipkin WI, Holmes EC, Garry RF (2020): The proximal origin of SARS-CoV-2. Nat. Med. 26,450-452. https://doi.org/10.1038/s41591-020-0820-9

Belouzard S, Chu VC, Whittaker GR (2009): Activation of the SARS coronavirus spike protein via sequential proteolytic cleavage at two distinct sites. Proc. Natl. Acad. Sci. USA 106, 5871-5876. https://doi.org/10.1073/ pnas.0809524106

Boni MF, Lemey P, Jiang X, Lam TTY, Perry BW, Castoe TA, Rambaut A, Robertson DL (2020): Evolutionary origins of SARS-CoV-2 sarbecovrius lineage responsible for the COVID-19 pandemic. Nature Microbiol. (in press). https://doi.org/10.1101/2020.03.30.015008

Cao Y, Cai K, Xiong L (2020): Corona Virus Disease 2019: A new severe acute respiratory syndrome from Wuhan in China. Acta Virol. 64, 210-215. https://doi.org/10.4149/ av_2020_201

Cui J, Li F, Shi ZL (2019): Origin and evolution of pathogenic coronaviruses. Nat. Rev. Microbiol.17,181-192. https:// doi.org/10.1038/s41579-018-0118-9

Dallavilla T, Bertelli M, Morresi A, Buchati V, Stuppia L, Beccari T, Chiurazzi P, Marceddu G (2020): Bioinformatic analysis indicates that SARS-CoV-2 is unrelated to known artificial Coronaviruses European Rev. Med. Pharm. Sci. 24, 4558-4564.

Decaro N, Lorusso A (2020): Novel human coronavirus (SARSCoV-2): A lesson from animal Coronaviruses. Vet. Microbiol. 244, 108693. https://doi.org/10.1016/j.vetmic.2020.108693

Frutos R, Serra-Cobo J, Chen T, Devaux CA (2020): COVID-19: Time to exonerate the pangolin from the transmis- 
sion of SARS-CoV-2 to humans. Infect. Genet. Evol. 84, 104493. https://doi.org/10.1016/j.meegid.2020.104493 Gorbalenya AE, Baker SC, Baric RS, de Groot RJ, Drosten C, Gulyaeva AA, Haagmans BL, Lauber C, Leontovich AM, Neuman BW, Penzar D, Perlman S, Poon LLM, Samborskiy D, Sidorov IA, Sola I, Ziebuhr J (2020): The species Severe acute respiratory syndrome-related coronavirus: classifying 2019-nCoV and naming it SARSCoV-2. Coronaviridae study group of the international committee on taxonomy of viruses. Nat. Microbiol. 5, 536-544. https://doi.org/10.1101/2020.02.07.937862

Hoffmann M, Kleine-Weber H, Schroeder S, Krüger N, Herrler T, Erichsen S, Schiergens TS, Herrler G, Wu NH, Nitsche A, Müller MA, Drosten C, Pöhlmann S (2020a): SARSCoV-2 cell entry depends on ACE2 and TMPRSS2 and is blocked by a clinically proven protease inhibitor. Cell, 181, 271-280. https://doi.org/10.1016/j.cell.2020.02.052

Hoffmann M, Kleine-Weber H, Pöhlmann S. (2020b): A Multibasic cleavage site in the spike protein of SARS-CoV-2 is essential for infection of human lung cells. Mol. Cell 78, 779-784. https://doi.org/10.1016/j.molcel.2020.04.022

Huang C, Wang Y, Li X, Ren L, Zhao J, Hu Y, Zhang L, Fan G, Xu J, Gu X, Cheng Z, Yu T, Xia J, Wei Y, Wu, W, Xie X, Yin W, Li H, Liu M, Xiao Y, Gao H, Guo L, Xie J, Wang G, Jiang R, Gao Z, Jin Q, Wang J, Cao B (2020): Clinical Features of Patients Infected With 2019 Novel Coronavirus in Wuhan, China. Lancet 395, 497-506. https://doi. org/10.1016/S0140-6736(20)30183-5

Chan JF, Lau SK, To KK, Cheng VC, Woo PC, Yuen KY (2015): Middle East respiratory syndrome coronavirus: another zoonotic betacoronavirus causing SARS-like disease. Clin. Microbiol. Rev. 28, 465-522. https://doi. org/10.1128/CMR.00102-14

Chan JFW, Kok KH, Zhu Z, Chu H, To KK, Yuan S, Yuen KY (2020): Genomic characterization of the 2019 novel humanpathogenic coronavirus isolated from a patient with atypical pneumonia after visiting Wuhan. Emerg. Microbes Infect. 28, 221-236. https://doi.org/10.1080/ 22221751.2020.1719902

Cheng VC, Lau SK, Woo PC, Yuen KY (2007): Severe acute respiratory syndrome coronavirus as an agent of emerging and reemerging infection. Clin. Microbiol. Rev. 20, 660-94. https://doi.org/10.1128/CMR.00023-07

Jaimes JA, Millet JK, Whittaker GR (2020): Proteolytic cleavage of the SARS-CoV-2 spike protein and the role of the novel S1/S2 Site. iScience 23, 101212. https://doi. org/10.1016/j.isci.2020.101212

Ji W, Wang W, Zhao X, Zai J, Li X (2020): Cross-species transmission of the newly identified coronavirus 2019-nCoV. J. Med. Virol. 92, 433-440. https://doi.org/10.1002/ ¡mv.25682

Kumar S, Maurya VK, Prasad AK, Bhatt MLB, Saxena SK (2020): Structural, glycosylation and antigenic variation between 2019 novel coronavirus (2019-nCoV) and SARS coronavirus (SARS-CoV). Virus Disease 31,13-21. https://doi.org/10.1007/s13337-020-00571-5

Lam TTY, Jia N, Zhang YW, Shum MHH, Jiang JF, Zhu HC, Tong YG, Shi YX, Ni XB, Liao YS, Li WJ, Jiang BG, Wei
W, Yuan TT, Zheng K, Cui XM, Li J, Pei GQ, Qiang X, Cheung WYM, Li LF, Sun FF, Qin S, Huang JC, Leung GM, Holmes EC, Hu YL, Guan Y, Cao WC (2020): Identifying SARS-CoV-2 related coronaviruses in Malayan pangolins. Nature 583,282-285. https://doi.org/10.1038/ s41586-020-2169-0

Lan J, Ge J, Yu J, Shan S, Zhou H, Fan S, Zhang Q, Shi X, Wang Q, Zhang L, Wang X (2020): Structure of the SARS-CoV-2 spike receptor-binding domain bound to the ACE2 receptor. Nature 581, 215-220. https://doi.org/10.1038/ s41586-020-2180-5

Letko M, Marzi A, Munster V (2020): Functional assessment of cell entry and receptor usage for SARS-CoV-2 and other lineage B betacoronaviruses. Nat. Microbiol.5,562-569. https://doi.org/10.1038/s41564-020-0688-y

Liu P, Chen W, Chen JP (2019): Viral Metagenomics Revealed Sendai Virus and Coronavirus Infection of Malayan Pangolins (Manis javanica). Viruses 11, 979. https:// doi.org/10.3390/v11110979

Liu P, Jiang JZ, Wan XF, Hua Y, Li L, Zhou J, Wang X, Hou F, Chen J, Zou J, Chen J (2020): Are pangolins the intermediate host of the 2019 novel coronavirus (SARS-CoV-2)? PLoS Pathog. 16, e1008421. https://doi.org/10.1371/journal. ppat.1008421

Lu R, Zhao X, Li J, Niu P, Yang B, Wu H, Wang W, Song H, Huang B, Zhu N, Bi Y, Ma X, Zhan F, Wang L, Hu T, Zhou H, Hu, Z, Zhou W, Zhao L, Chen J, Meng Y, Wang J, Lin Y, Yuan J, Xie Z, Ma J, Liu WJ, Wang D, Xu W, Holmes EC, Gao GF, Wu G, Chen W, Shi W, Tan W (2020a): Genomic characterisation and epidemiology of 2019 novel coronavirus: implications for virus origins and receptor binding. Lancet 395, 565-574. https://doi.org/10.1016/ S0140-6736(20)30251-8

Lu H, Stratton CW, Tang YW (2020b): Outbreak of Pneumonia of Unknown Etiology in Wuhan, China: The Mystery and the Miracle J. Med. Virol. 92, 401-402. https://doi. org/10.1002/jmv.25678

Ou X, Liu Y, Lei X, Li P, Mi D, Ren L, Guo L, Guo R, Chen T, Hu J, Xiang Z, Mu Z, Chen X, Chen J, Hu K, Jin Q, Wang J, Qian Z (2020): Characterization of spike glycoprotein of SARS-CoV-2 on virus entry and its immune crossreactivity with SARS-CoV. Nat. Commun. 11, 1620. https://doi.org/10.1038/s41467-020-15562-9

Pradhan P, Pandey AK, Mishra A, Gupta P, Tripathi PK, Menon MB, Gomes J, Vivekanandan P, Kundu B (2020): Uncanny similarity of unique inserts in the $2019-\mathrm{nCoV}$ spike protein to HIV-1 gp120 and Gag. BioRxiv 2020, https://doi.org/10.1101/2020.01.30.927871

Sabir JSM., Lam TT-Y, Ahmed MMA, Li L, Shen Y, Abo-Aba SEM, Qureshi MI, Abu-Zeid M, Zhang Y, Khiyami MA, et al (2016): Co-circulation of three camel coronavirus species and recombination of MERS-CoVs in Saudi Arabia. Science 351, 81-84. https://doi.org/10.1126/ science.aac8608

Shang J, Wan Y, Luo C, Ye G, Geng Q, Auerbach A, Li F (2020a): Cell entry mechanisms of SARS-CoV-2. Proc Natl Acad Sci USA, 117, 11727-11734. https://doi.org/10.1073/ pnas.2003138117 
Shang J, Ye G, Shi K, Wan Y, Luo C, Aihara H, Geng Q, Auerbach A, Li F (2020b): Structural basis of receptor recognition by SARS-CoV-2. Nature 581, 221-224. https://doi. org/10.1038/s41586-020-2179-y

Walls AC, Park YJ, Tortorici MA, Wall A, McGuire AT, Veesler D (2020): Structure, Function, and Antigenicity of the SARS-CoV-2 Spike Glycoprotein. Cell 181, 281-292. https://doi.org/10.1016/j.cell.2020.02.058

Wan Y, Shang J, Graham R, Baric RS, Li F (2020): Receptor Recognition by the Novel Coronavirus from Wuhan: an Analysis Based on Decade-Long Structural Studies of SARS Coronavirus. J. Virol. 94, e00127-20. https://doi. org/10.1128/JVI.00127-20

Wang Q, Zhang Y, Wu L, Niu S, Song C, Zhang Z, Lu G, Qiao C, Hu Y, Yuen KY, Wang Q, Zhou H, Yan J, Qi J (2020a): Structural and Functional Basis of SARS-CoV-2 Entry by Using Human ACE2. Cell 181, 894-904. https://doi. org/10.1016/j.cell.2020.03.045

Wang J, Xu X, Zhou X, Chen P, Liang H, Li X, Zhong W, Hao P (2020b): Molecular simulation of SARS-CoV-2 spike protein binding to pangolin ACE2 or human ACE2 natural variants reveals altered susceptibility to infection. J. Gen. Virol. https://doi.org/10.1099/igv.0.001452

Watanabe Y, Allen JD, Wrapp D, McLellan JS, Crispin M (2020): Site-specific glycan analysis of the SARS-CoV-2 spike. Science 369, 330-333. https://doi.org/10.1126/science. abb9983

WHO. Coronavirus disease 2019. https://www.who.int/emergencies/diseases/novelcoronavirus-2019 (Feb 18, 2020).

Wrapp D, Wang N, Corbett KS, Goldsmith JA, Hsieh CL, Abiona O, Graham BS, McLellan JS (2020): Cryo-EM structure of the 2019-nCoV spike in the prefusion conformation. Science 367, 1260-1263. https://doi.org/10.1126/ science.abb2507

Wrobel AG, Benton DJ, Xu P, Roustan C, Martin SR, Rosenthal PB, Skehel JJ, Gamblin SJ (2020): SARS-CoV-2 and bat RaTG13 spike glycoprotein structures inform on virus evolution and furin-cleavage effects. Nat. Struct. Mol. Biol. 27, 763-767. https://doi.org/10.1038/s41594-020$\underline{0468-7}$

Wu F, Zhao S, Yu B, Chen YM, Wang W, Song ZG, Hu Y, Tao ZW, Tian JH, Pei YY, Yuan ML, Zhang YL, Dai FH, Liu Y, Wang QM, Zheng JJ, Xu L, Holmes EC, Zhang YZ (2020): A new coronavirus associated with human respiratory disease in China. Nature 579, 265-269. https://doi. org/10.1038/s41586-020-2008-3

Xiao C, Li X, Liu S, Sang Y, Gao SJ, Gao F (2020a): HIV-1 did not contribute to the 2019-nCoV genome. Emerg. Microbes Infect. 9, 378-381. https://doi.org/10.1080/22221751.2 $\underline{020.1727299}$

Xiao K. Zhai J, Feng Y, Zhou N, Zhang X, Zou JJ, Li N, Guo Y, Li X, Shen X, Zhang Z, Shu F, Huang W, Li Y, Zhang Z, Chen
RA, Wu YJ, Peng SM, Huang M, Xie WJ, Cai QH, Hou FH, Chen W, Xiao L, Shen Y (2020b): Isolation of SARS-CoV2-related coronavirus from Malayan pangolins. Nature 283,286-289. https://doi.org/10.1038/s41586-020-2313-x

Yan R, Zhang Y, Li Y, Xia L, Guo Y, Zhou Q (2020): Structural basis for the recognition of SARS-CoV-2 by full-length human ACE2. Science 367, 1444-1448. https://doi. org/10.1126/science.abb2762

Yuan M, Wu NC, Zhu X, Lee CD, So RTY, Lv H, Mok CKP, Wilson IA (2020): A highly conserved cryptic epitope in the receptor binding domains of SARS-CoV-2 and SARSCoV. Science 368, 630-633. https://doi.org/10.1126/ science.abb7269

Zhai X, Sun J, Yan Z, Zhang J, Zhao J, Zhao Z, Gao Q, He WT, Veit M, Su S (2020): Comparison of SARS-CoV-2 spike protein binding to ACE2 receptors from human, pets, farm animals, and putative intermediate hosts. J. Virol. JVI.00831-20. https://doi.org/10.1101/2020. $\underline{05.08 .084061}$

Zhang YZ, Holmes EC (2020): A Genomic Perspective on the Origin and Emergence of SARS-CoV-2. Cell 181, 223-227. https://doi.org/10.1016/j.cell.2020.03.035

Zhang C, Zheng W, Huang X, Bell EW, Zhou X, Zhang Y (2020a): Protein structure and sequence reanalysis of 2019$\mathrm{nCoV}$ genome refutes snakes as its intermediate host and the unique similarity between its spike protein insertions and HIV1. J. Proteome Res. 19, 1351-1360. https://doi.org/10.1021/acs.jproteome.0c00129

Zhang T, Wu Q, Zhang Z (2020b): Probable Pangolin Origin of SARS-CoV-2 Associated with the COVID-19 Outbreak. Curr. Biol. 30, 1-6. https://doi.org/10.1016/j. cub.2020.03.063

Zhou P, Yang XL, Wang XG, Hu B, Zhang L, Zhang W, Si HR, Zhu Y, Li B, Huang CL, Chen HD, Chen J, Luo Y, Guo H, Jiang RD, Liu MQ, Chen Y, Shen XR, Wang X, Zheng XS, Zhao K, Chen QJ, Deng F, Liu LL, Yan B, Zhan FX, Wang YY, Xiao GF, Shi ZL (2020a): A pneumonia outbreak associated with a new coronavirus of probable bat origin. Nature 579, 270-273. https://doi.org/10.1038/ s41586-020-2012-7

Zhou H, Chen X, Hu T, Li J, Song H, Liu Y, Wang P, Liu D, Yang J, Holmes EC, Hughes AC, Bi Y, Shi W (2020b): A novel bat coronavirus closely related to SARS-CoV-2 contains natural insertions at the S1/S2 cleavage site of the spike protein. Curr. Biol. 30, 2196-2203. https://doi. org/10.1016/i.cub.2020.05.023

Zhu N, Zhang D, Wang W, Li X, Yang B, Song J, Zhao X, Huang B, Shi W, Lu R, Niu P, Zhan F, Ma X, Wang D, Xu W, Wu G, Gao GF, Tan W (2020): Novel Coronavirus Investigating and Research Team. A Novel Coronavirus from Patients with Pneumonia in China, 2019. N. Engl. J. Med. 382, 727-733. https://doi.org/10.1056/NEJMoa2001017 